\title{
Suggestions on Improving the Basic Translation Ability of Navigation Majors
}

\author{
Yuan Gao \\ Shandong Jiaotong University, Weihai, China
}

Keywords: Navigation majors; College English teaching; Basic translation ability

\begin{abstract}
The level of English application of seafarers in China is generally not high. In order to improve the basic translation ability of maritime students, the paper analyzes the problems of nautical students in basic translation and puts forward some suggestions and countermeasures on how to solve related problems.
\end{abstract}

\section{Introduction}

In order to improve the basic translation ability of the navagation graduates, the article analyzes the problems they have and try to give some advice and solutions on these subjects.With the development of the international shipping industry, the status and role of English as a working language in the industry has become increasingly prominent. The International Maritime Organization will be able to use maritime English fluently as a necessary quality for senior crew and shipping managers. Shipowners will also be able to use English proficiently as an important criterion for assessing and selecting crew members. However, studies have shown that the overall level of English for our crew is not optimistic. The basic English skills of some maritime graduates are not solid, and there are still great difficulties in using English for communication and communication in work practice. The author believes that a qualified maritime professional graduate should be a qualified maritime English translator.

\section{The current problems in the English translation teaching of marine majors}

Luo Xuanmin (2002) divided the teaching objects of translation into two categories: university translation teaching and professional translation teaching according to the professional attributes of learners. At present, the focus of translation teaching focuses on the latter, while the former is on the margins of research. As far as maritime majors are concerned, the current research on translation in China is mostly focused on the translation studies of maritime legal English and maritime English. There are few studies on English translation of maritime colleges. For a long time, translation has always been a weak link in college English teaching for maritime majors. The reasons for this mainly include the following aspects:

\subsection{Neglect of teaching guidance}

\subsubsection{The influence of the educational institutions at all levels on the guiding ideology}

Over the years, the education authorities at all levels in China have placed more emphasis on the teaching of English listening and speaking skills in view of the negative phenomena such as "dumb English" in previous years. For example, the "Teaching English Course Requirements" issued by the Ministry of Education in 2007, although it has requirements for listening, speaking, reading, writing, translating and recommending vocabulary in college English, it emphasizes "college English" in the teaching objectives. The teaching goal is to develop students' comprehensive English application ability, especially the ability of listening and speaking, so that they can communicate effectively in English in future study, work and social interaction...". Perhaps the Ministry of Education's intention is not to ignore the status of "translation", but as a guiding provision, it will give misunderstandings to educational institutions and weaken the status of translation in teaching. 


\subsubsection{The influence of various teaching materials}

At present, there are many kinds of textbooks about college English in China, but no matter which version of the textbooks, it is difficult to see comprehensive systematic translation knowledge, method guidance and skill training. Most of the textbooks only have a small number of English-Chinese translations and Chinese-English translation exercises around the text content in the supporting exercises. When teachers implement teaching according to the textbooks, they naturally neglect the translation.

\subsection{The negative effects of the CET-4 test}

The CET- 4 has been in use since 1987 and has been in existence for more than 20 years. It has a great impact on college English teaching in China. In the CET-4 test, translation only accounts for 5\% of the total score, and the lowest proportion among the various types of questions. From the perspective of exam-taking, most teachers focus on vocabulary explanations, intensive listening exercises, and teaching test-taking skills, and rarely involve translation techniques and translation methods; students lack understanding of the differences between English and Chinese, sometimes Can understand the original text but do not understand the translation skills, in the translation of certain long sentences difficult sentences, passive structures and attributive clauses, adverbial clauses and other sentence patterns appear to be helpless, resulting in translation imperfections or expression errors. These are not conducive to the improvement of students' basic translation skills.

\subsection{Suggestions on improving the basic translation ability of maritime majors}

Higher requirements can be used to excerpt the English literature of the majors, and can use the dictionary to translate articles with familiar themes in the popular newspapers of the English-speaking countries. The translations are fluent, and the understanding and language expression errors are less. Ability to use appropriate translation skills. About 350 English words per hour. About 300 Chinese characters per hour. It can be seen that the Ministry of Education has given clear guidance on the difficulty, subject matter, speed of translation, and quality requirements of translation materials. What is more worth mentioning is that it increases the requirements for mastery of translation skills. Therefore, the "Course Requirements" provides a practical basis for the construction and design of English translation teaching for maritime colleges, teaching arrangements and testing organizations, thus providing theoretical guidance and guarantee for further helping students improve their translation skills.

\section{Introduction of translation skills and translation methods in textbook compilation}

When selecting college English textbooks, maritime professional colleges can choose or compile teaching materials according to their professional characteristics. For example, the new-field college English textbook currently used by the maritime majors has only five Chinese-English translations and five English-Chinese translation exercises. The author suggests that translation should be considered as an important language skill when writing textbooks. You may wish to refer to the design of the vocabulary practice design and reading method guidance section, and add basic translation knowledge and techniques in the translation practice, such as common sentence syntax, syntactic, positive and negative and anti-orthogonal methods, word-based translation, word-adding, Basic content such as minus lexical, word meaning selection, extension and ambiguity.

\subsection{Teachers explore effective teaching methods in teaching practice}

College English teachers can purposely select some sentences or paragraphs in each text to conduct targeted translation training for students. Before the class, students can self-learn the text by checking the reference books and checking the information on the Internet. During the class, the students can translate the sentences or paragraphs, and analyze the English meaning, sentence structure and text layout to make students understand the translation knowledge. And skills, teachers can properly comment or organize everyone to discuss. This not only tests the students' understanding of the text, but also consolidates the students' knowledge of the text. After class, 
teachers can also encourage students to do more translation exercises. The so-called practice makes perfect and accumulates translation knowledge in practice.

\subsection{Help students build a cross-cultural knowledge structure}

The famous American translation theorist Eugene Nida once said: "Translation is the exchange between two cultures. For a truly successful translation, it is even more important to be familiar with two cultures than to master two languages. Because words are only The cultural context of its role makes sense.” Many students know very little about the vast differences between Chinese and Western cultures during the middle school years. The author has held talks on more than 200 nautical freshmen, and found that $87 \%$ of the students who know nothing about English culture allusions, only $13 \%$ of students are only a little understanding through English movies and American drama. In this context, students often inevitably have jokes that are misinterpreted due to lack of understanding of culture, such as the translation "I have let the cat out of the bag already, and I might as well tell the whole thing now." I have already leaked the secret, I will tell you all about it now.) When some students don't understand let the cat out of the bag is an idiom, it's translated as "I have let the cat out of my pocket, I Let me tell you all about it now." Such a translation will inevitably make readers confused and unintelligible. Therefore, teachers should pay attention to the cultural background knowledge of English and Chinese, especially the background knowledge related to politics, customs, religion and history and culture.

\subsection{Focus on the organic combination of translation and other language skills}

The cultivation of translation ability is not carried out in isolation, and should be organically combined with the basic skills of listening, speaking, reading and writing. For example, it is necessary to strengthen vocabulary and grammar teaching to help students lay a solid foundation in language learning; to strengthen reading and listening and writing training, to increase students' language input and language output.

\section{Pay attention to improving the Chinese literacy of students majoring in navigation}

Many maritime students have so-called translations when translating from English to Chinese, such as mismatching, excessive use of passive sentences, logical confusion, lack of understanding of the original text, and excessive personal translation. By analyzing and correcting examples, teachers can help students consciously circumvent these problems in future exercises. In addition, in view of the engineering characteristics of the maritime profession, teachers should encourage students to read more classic Chinese works and Chinese reports on political, economic, cultural, scientific and other topics, learn authentic Chinese expressions, broaden their knowledge, and astronomy.

\section{Conclusion}

The foreign-related nature of the maritime profession determines the importance of English in the student's future career. Translation ability is an important ability that students must have in the process of learning college English. College English teachers should help students improve their translation from the perspectives of curriculum teaching requirements, teaching materials construction, teaching methods, and improving students' Chinese literacy in translation teaching practice. Level. Only by improving the basic translation ability of maritime students can they ensure that they meet the needs of international shipping companies for talents when they graduate, and enhance the competitiveness of Chinese crew members in the international seafarers' labor market.

\section{References}

[1] Neubert, Albrecht. Competence in language, in languages, and in translation [A]. In Christina Schaffner and Beverly Adab (eds.). Developing Translation Competence [C]. Amsterdam: John 
Benjamins, 2000: 3- 18.

[2] Murray. Research on Chinese Translation Teaching [M]. Shanghai Foreign Language Education Press, 1999:3

[3] Xu Jianping. Looking at the lack of students' translation ability from CET-4 translation test [J]. Chinese translation, 2000(6)

[4] Chen Changyong, Gao Lei. Reflections on English Translation Teaching for Non-English Majors[J]. Heilongjiang Higher Education Research, 2003(4) 